\title{
Evaluating of the Effectiveness of Television Advertisement of Life Insurance and Investing in Ma Insurance Company
}

\author{
Nima Rahmani ${ }^{1}$ \\ ${ }^{1}$ Islamic Azad University, Iran \\ Correspondence: Nima Rahmani, Master of Comercial Management (Insurance), Abhar Branch, Islamic Azad \\ University, Abhar, Iran. E-mail: esfehani.mohamad3@gmail.com
}

Received: September 27, 2016

Accepted: October 18, $2016 \quad$ Online Published: October 21, 2016

doi:10.5539/mas.v10n12p222

URL: http://dx.doi.org/10.5539/mas.v10n12p222

\begin{abstract}
Nowadays, corporates require purposeful and effective marketing activities to survive and sell their goods and services in this ever-growing competitive world. Marketing is an issue having a significant role in marketing process of a corporate and it is dedicated a huge amount of marketing budget. Measuring effectiveness can be implemented through considering three steps: advertising inputs (e.g. advertising intensity, advertising content, and advertising budget); mental processing of customers during and after the ads broadcast; and finally advertising outcomes (e.g. resulting change in sales, income, and profit). In addition to the measurement of ads effectiveness on the customers mind, in the present study the impact of such ads on the sales was also tackled based on the AIDA hierarchy of effects model. Four hypotheses were considered for testing the research model. After the reliability and validity confirmation by, respectively, Cronbach's alpha and content validity, 400 questionnaires were distributed amongst the customers of "Ma" insurance company in Tehran, chosen base on the simple random sampling. Due to the rejection of data normality hypothesis, two Wilcoxon non-parametric tests, namely sign test and signed-rank test, were used. After statistical tests, hypotheses 3 and 4 (i.e. ads effectiveness on individuals willingness and action) were rejected. Finally, following the interpretations of results obtained from data analysis, the practical recommendations were presented for corporates and advertisers.
\end{abstract}

Keywords: marketing, service marketing, promotion, advertising, effectiveness

\section{Introduction}

Marketing is one of the tools having a crucial role in meeting the objectives in the corporates. Needless to say, the corporates activity continuation is impossible without marketing and advertising for sales (Kotler, 2006). Moreover, one of the significant issues in advertising domain is its effectiveness. Advertisers and marketers are continuously interested in determining the impact of their advertisement upon the final customers (Fortin, 1997). In today competitive environment, the cost of advertising in media is increasing, and simultaneously, their effectiveness is decreasing due to the sever competition among the different and/or similar goods and services providers (Amiri, 2006). Albeit, advertising has turned into a matter of great necessity for all corporates and organizations, it does not necessarily mean that any type of advertising is effective. Measuring the impacts of ads can reveal the strengths and weaknesses of them. Moreover, the results of such ads may be used in planning, alteration and modification of advertising activities, and also ineffective costs, risks and activities can be avoided (Harati Sani, 2006).

Unfortunately, in Iran, measuring advertising effectiveness receives less attention due to the newness of the advertising industry, lack of required information, lack of managers familiarity with the patterns and models of advertising effectiveness assessment, and lack of applied samples in this area (Houshmandi et al, 2005). Similarly, the aforementioned problem is true about insurances having shifted to advertising due to the intensification of competition, and annually spending a great amounts of money on it. Therefore, acquiring information in terms of the amount and the way of the effectiveness of the spent money on the advertising sector is a matter of great importance for insurance companies (Amiri, 2006).

Amongst the advertising tools and media, TV as a medium covering a host of people has a great influence on families.

Due to the ambiguities in terms of different types of advertising measurement methods and procedures, a group 
of advertising brokers have accepted some principles as advertising guideline, which determine the methodology of assessing advertising effectiveness and provide some patterns to evaluate the latter (Roosta, 2000). The aim of advertising is frequently to promote the rate of goods or service sales. To this end, a message has to be prepared in line with the latter, it has to be provided for the people in question by using an appropriate tool, and its effectiveness has to be evaluated for future usage and required adjustments, i.e. a decision in terms of whether to preserve the current advertising methods or to revise the existing procedures (Irandoost Saneie, 2005). Proper planning, monitoring and control on the advertising may depend the measurement criteria of effectiveness. The matter of the fact is that, there are substantially limited fundamental studies on the advertising effectiveness, maybe merely more than 2.0 of $1 \%$ of the total advertising budget spends on the gaining knowledge in terms of the way of spending the remaining $99.8 \%$ of the budget.

Most of the measurement criteria of advertising effectiveness have applicable nature, and merely deal with special ads and advertising programs. Advertising agencies spend a great deal of money on the advertising pre-test; however, they fail to dedicate sufficient budget for investigating and assessing the resulting impacts. Most companies provide advertising plans, implement them in the public market, and then evaluate their effectiveness. In 2012, Ma insurance company has broadcasted 356 teasers on national channels for 4850 seconds. Likewise, it has broadcasted 1575 teasers on provincial channels for 59885 seconds. In 2012, the great proportion of budget has dedicated to the company advertising. Given the above-mentioned statistics, and also considering the great cost undertaken by the company for advertising, investigating and assessing the advertising effectiveness is inevitable.

The present study includes four hypotheses as follows:

1. TV ads of Ma Insurance Company have been effective in attracting customers.

2. TV ads of Ma Insurance Company have been effective in people interest in life insurance and investing.

3. TV ads of Ma Insurance Company have been effective in people willingness to purchase.

4. TV ads of Ma Insurance Company have been effective in life insurance purchase and investing by people.

The present study aims at investigating the effectiveness of TV advertisement on life insurance and investing of the Ma Insurance Company

\section{Research Methodology}

The present study is applied, from the perspective of purpose, and survey-descriptive, from that of the data collection method. In this study the data was compiled through questionnaire. The respective questionnaire was distributed among the customers of life insurance and investing of Ma Insurance Company.

Three elements of content, scope and time were taken into account for selecting statistical population including all customers of Insurance Company Ma.

As the considered society in this research is indefinite, random sampling was used to compute the required sample size. In addition, Cochran formula was used to determine the sample size. The confidence level in the present study was computed $95 \%$.

Advertising is a form of impersonal communication, provided by mass media through receiving money from a special financial sponsorship to stimulate audience or affect the latter (Ghorbanloo, 2004, p.43). Therefore, advertising consists of six elements: firstly, it is a form of communication; secondly, it is an impersonal communication due to its massive nature, i.e. the advertisement fails to be designed for a special person; thirdly, money is paid for its provision; fourthly, the sponsorship (advertiser) is determined; fifthly, the ad is provided by mass media; and finally, the ad is broadcasted for evoking audiences and affect them as well. Advertising can be used to establish a long-term image of a product or to commence a rapid and short-term sale. Advertising can be efficiently accessed by purchasers who are geographically dispersed. Apart from the advertising broadcaster, ads could influence the sale provided that consumers believe that the brand advertised has a favorable value (Kotler, 2005, p.580).

Well planning and control may depend on the advertising effectiveness (Kotler,2006,p583). Advertising could have diverse impacts upon the thoughts, attitudes, emotions, and behaviors of man. Researchers use different tools for assessing the ads and their impacts as well. Understanding the advertisement way of working may require the description of variables and determination of their relations as well (Tellis,2003, p.43). The measurement criteria of advertising effectiveness in the respective literature is extremely variable and debatable, for different theories and approaches have been applied (Kelly \& Turley, 2004). 


\section{The Conceptual Model of Life Insurance and Investing Ads Effectiveness of Ma Insurance Company}

In the present study, AIDA model was used to evaluate the advertising effectiveness. The aforementioned model is one of the Hierarchy of Effects Models, measuring the advertising social interaction from four aspects of attraction, interest, willingness and action.

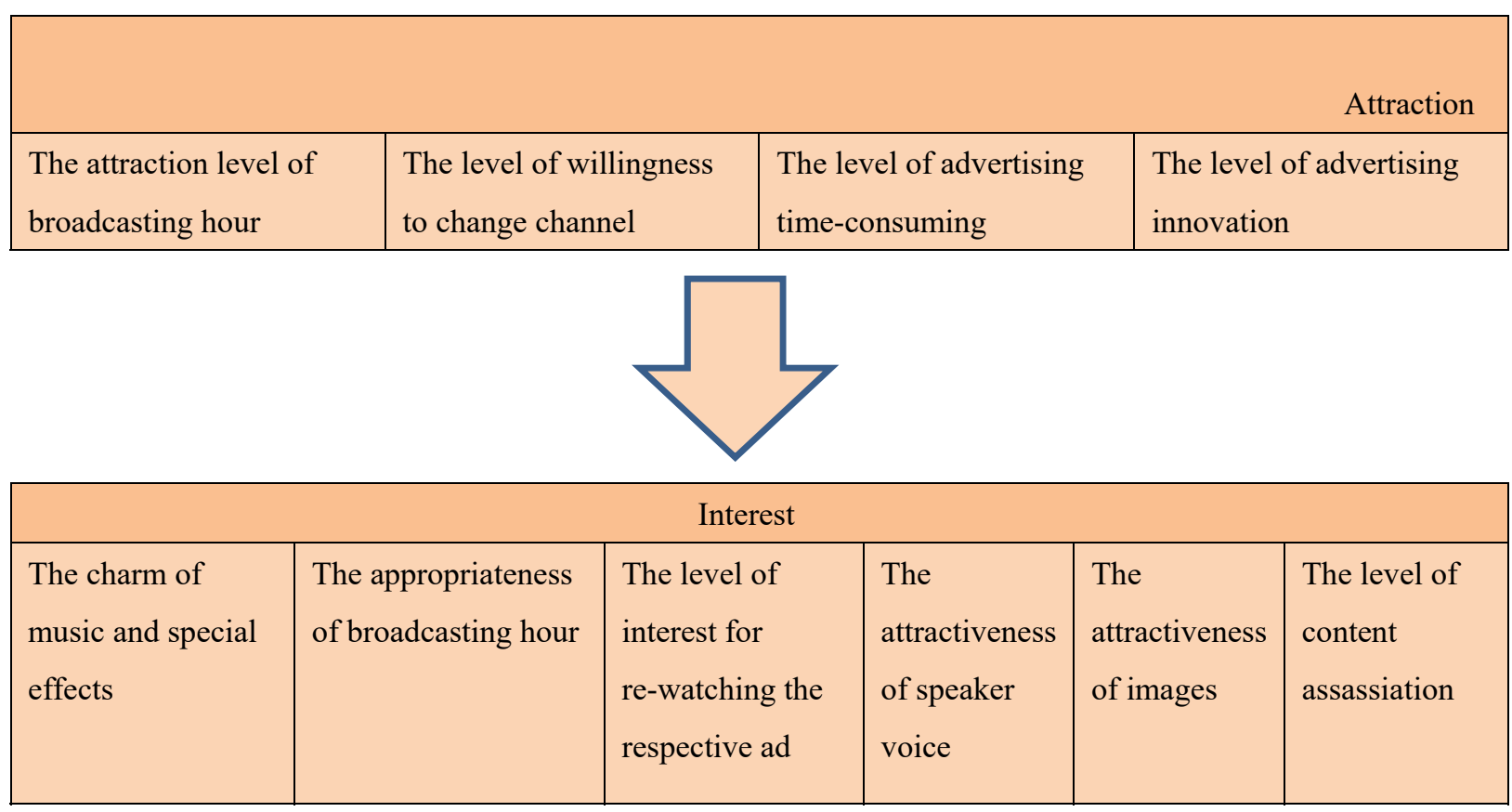

\begin{tabular}{|l|l|l|l|}
\hline \multicolumn{5}{|c|}{ Willingness } \\
\hline $\begin{array}{l}\text { The level of realization of } \\
\text { the advertising in the } \\
\text { audience eyes }\end{array}$ & $\begin{array}{l}\text { The level of creating } \\
\text { positive mindset towards } \\
\text { the product }\end{array}$ & $\begin{array}{l}\text { The amount of product } \\
\text { features informing }\end{array}$ & $\begin{array}{l}\text { The compatibility of the } \\
\text { product with the needs }\end{array}$ \\
\hline
\end{tabular}

\begin{tabular}{|l|l|l|l|}
\hline \multicolumn{4}{|c|}{ Action } \\
\hline $\begin{array}{l}\text { The level of product } \\
\text { recommendation to others }\end{array}$ & $\begin{array}{l}\text { The level of persuasion } \\
\text { for buying }\end{array}$ & $\begin{array}{l}\text { The level of search about } \\
\text { the product }\end{array}$ & $\begin{array}{l}\text { The level of affordability } \\
\text { of the respective product }\end{array}$ \\
\hline
\end{tabular}

Figure 1.

\section{Research Findings}

1. Investigating the sample specifications

2. The gender of respondents: more that $54 \%$ of respondents are men. 
3. The marital state of the respondents: the ratio of married respondents to single ones is approximately equal.

4. The education level of respondents: less than $10 \%$ of respondents are lower diploma. Respondents with B.A. degree have the highest frequency with more that $40 \%$. 6\% of respondents have PhD. or more.

5. The age range of respondents: less than $12 \%$ of respondents are lower than 20 years. 20-30 years respondents have the highest frequency with $40 \%$. Less than $8 \%$ of respondents are more than 50 years.

6. The respondents occupation: self-employed respondents with $45 \%$ have the highest frequency

Hypothesis (1) testing:

Hypothesis 1: TV ads of Ma Insurance Company have been effective in attracting customers.

The statistical expression of the hypothesis:

$$
\left\{\begin{array}{l}
H_{0}: \tilde{m}_{1} \leq 3 \\
H_{1}: \tilde{m}_{1}>3
\end{array}\right.
$$

In the above mentioned relation, $m l$ refers to "customers attraction" middle change. As it was mentioned earlier, if $m 1$ is more than 3 (equivalent of "very high" or "high" in the questionnaire for the questions associated with this variable), it simply means that the respective variable has a significant impact

Table 1.

\begin{tabular}{|c|c|c|c|c|c|c|}
\hline \multicolumn{3}{|c|}{ Wilcoxon test } & \multicolumn{4}{|c|}{ Sign test } \\
\hline & 36367 & Wilcoxon test & & $(61-26-232)$ & Sign indicators (less & $\begin{array}{r}\text { than, equal to, } \\
\text { greater than) }\end{array}$ \\
\hline & $3 / 50$ & $\begin{array}{r}\text { Median } \\
\text { estimated }\end{array}$ & & $3 / 67$ & & Median \\
\hline & $0 / 000$ & $\begin{array}{r}\text { Probability } \\
\text { value }\end{array}$ & & $0 / 000$ & & The probability \\
\hline Null & $\begin{array}{c}\text { hypotheses is } \\
\text { rejected }\end{array}$ & Test result & Null & $\begin{array}{r}\text { hypotheses is } \\
\text { rejected }\end{array}$ & & Test result \\
\hline
\end{tabular}

Decision making: In this section, the results of significance level of insurance advertising effectiveness in "customers attraction" element are estimated using Sign test and Wilcoxon test. In this test, the null hypothesis is rejected. Hence, it can be concluded that hypothesis 1 is confirmed, i.e. TV ads of Ma Insurance Company have been effective in attracting customers.

Hypothesis (2) testing:

Hypothesis 2: TV ads of Ma Insurance Company have been effective in people interest in life insurance and investing

The statistical expression of the hypothesis:

$$
\left\{\begin{array}{l}
H_{0}: \tilde{m}_{2} \leq 3 \\
H_{1}: \tilde{m}_{2}>3
\end{array}\right.
$$

In the above mentioned relation, $m 2$ refers to "the customers interest in life insurance and investing" middle change. As it was mentioned earlier, if $m 2$ is more than 3 (equivalent of "very high" or "high" in the questionnaire for the questions associated with this variable), it simply means that the respective variable has a significant impact.

The result of statistical test 
Table 2.

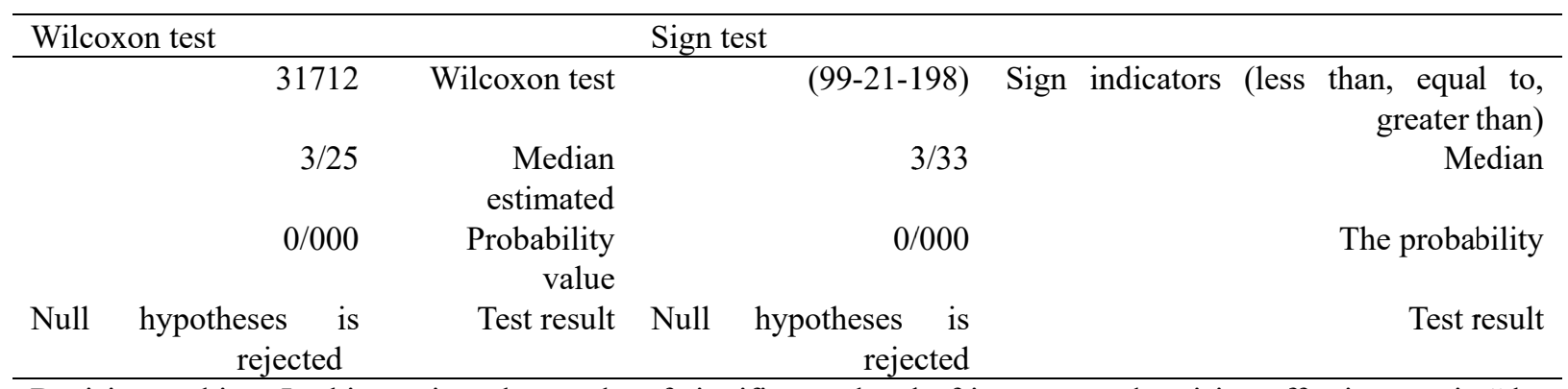

Decision making: In this section, the results of significance level of insurance advertising effectiveness in "the customers interest in life insurance and investing" element are estimated using Sign test and Wilcoxon test. In this test, the null hypothesis is rejected. Hence, it can be concluded that hypothesis 1 is confirmed, i.e. TV ads of Ma Insurance Company have been effective in people interest in life insurance and investing.

Hypothesis (3) testing:

Hypothesis 3: TV ads of Ma Insurance Company have been effective in people willingness to purchase.

The statistical expression of the hypothesis:

$$
\left\{\begin{array}{l}
H_{0}: \tilde{m}_{3} \leq 3 \\
H_{1}: \tilde{m}_{3}>3
\end{array}\right.
$$

In the above mentioned relation, $m 3$ refers to "the customers willingness to life insurance and investing" middle change. As it was mentioned earlier, if $m 3$ is more than 3 (equivalent of "very high" or "high" in the questionnaire for the questions associated with this variable), it simply means that the respective variable has a significant impact.

The result of statistical test

Table 3.

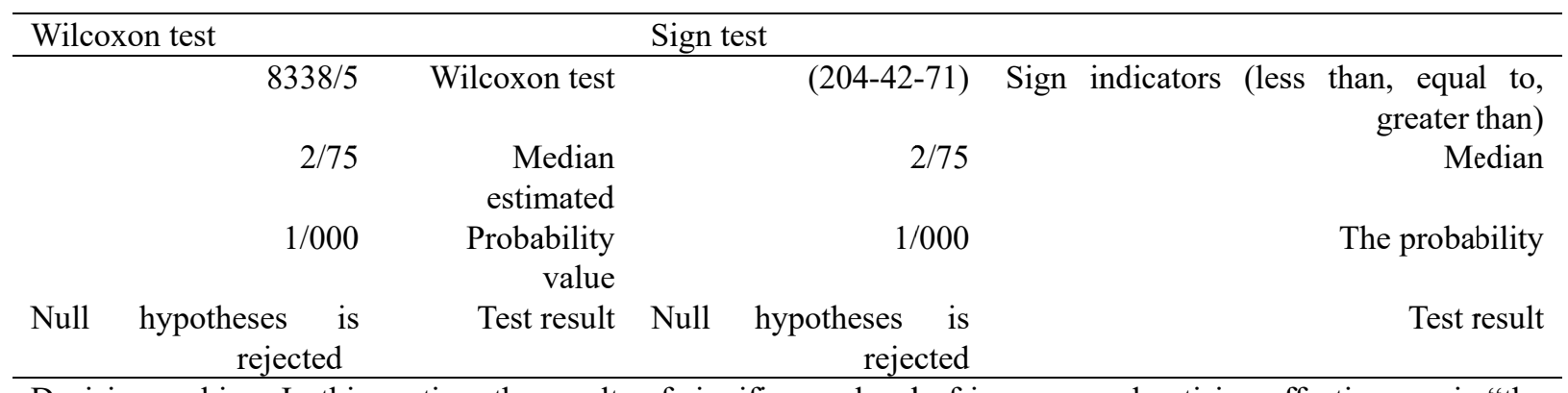

Decision making: In this section, the results of significance level of insurance advertising effectiveness in "the customers willingness to purchase life insurance and investing" element are estimated using Sign test and Wilcoxon test. In this test, the null hypothesis is confirmed. Hence, it can be concluded that hypothesis 1 is rejected, i.e. TV ads of Ma Insurance Company have failed to be effective in people interest in life insurance and investing.

Hypothesis (4) testing:

Hypothesis 4: TV ads of Ma Insurance Company have been effective in life insurance purchase and investing by people.

The statistical expression of the hypothesis:

$$
\left\{\begin{array}{l}
H_{0}: \tilde{m}_{4} \leq 3 \\
H_{1}: \tilde{m}_{4}>3
\end{array}\right.
$$


In the above mentioned relation, $m 34$ refers to "purchasing life insurance and investing" middle change. As it was mentioned earlier, if $m 4$ is more than 3 (equivalent of "very high" or "high" in the questionnaire for the questions associated with this variable), it simply means that the respective variable has a significant impact.

The result of statistical test

Table 4.

\begin{tabular}{|c|c|c|c|c|c|c|}
\hline \multicolumn{3}{|c|}{ Wilcoxon test } & \multicolumn{4}{|c|}{ Sign test } \\
\hline \multirow[b]{4}{*}{ Null } & $2630 / 5$ & Wilcoxon test & & $(257-27-33)$ & Sign indicators (less & $\begin{array}{l}\text { than, equal to, } \\
\text { greater than) }\end{array}$ \\
\hline & $2 / 75$ & $\begin{array}{r}\text { Median } \\
\text { estimated }\end{array}$ & & $2 / 25$ & & Median \\
\hline & $1 / 000$ & $\begin{array}{r}\text { Probability } \\
\text { value }\end{array}$ & & $1 / 000$ & & The probability \\
\hline & $\begin{array}{c}\text { hypotheses is } \\
\text { rejected }\end{array}$ & Test result & Null & $\begin{array}{r}\text { hypotheses is } \\
\text { rejected }\end{array}$ & & Test result \\
\hline
\end{tabular}

\section{Results}

\section{Hypothesis 1:}

TV ads of life insurance and investing of Ma Insurance Company have been effective. As it is observed, the null hypothesis in hypothesis 1 in both tests is rejected. Thence, advertising is effective in attracting people. It may be concluded that customers of Ma Insurance Company (the people in the society purchasing us at least one time) draw attention to our ads as soon as they faced it, for they were already familiar with our insurance. The customers considered the ads creative and time-saving.

Regarding the remarks outlined above, it can be claimed that TV ads had a direct and favorable impact on the products introducing of Ma Insurance Company such as life insurance and investing.

The results are totally consistent with the management considerations, i.e. the advertising impact on attracting $50 \%$ of Ma insurance company customers, this state was also confirmed in a separate test examining the ratio of two communities.

Hypothesis 2:

TV ads of life insurance and investing of Ma Insurance Company have been effective in customers interest. As it is observed, the null hypothesis in this hypothesis is rejected. In other words, like the hypothesis 1 , hypothesis 2 is also confirmed. Both tests used in the study also confirm that customers showed interest to the advertising and the ads components, e.g. images, music, voices played, special effects, and the ads time, i.e. they seem to be desired for the customers. Furthermore, the customers were interested in watching again the respective ad due to its visual and vocal attractiveness.

Regarding the results of Wilcoxon and sign tests, it is evident that advertising met the advertising aims and management considerations in making customers interested in the ad, i.e. influencing on $40 \%$ of customers.

Hypothesis 3:

TV ads of life insurance and investing of Ma Insurance Company have been effective in customers willingness to purchase life insurance and investing. Given the results presented in the respective table, there is no reason to reject the null hypothesis, hence the hypothesis 3 is rejected. It simply means that customers failed to favorably contact with the product advertised. It appears that advertising fail to provide sufficient information for the customers to attract them into purchasing due to a number of reasons including the complexity of life insurance and investing, the need for detailed and personal explanations, and the need for simultaneously responding the questions posed. According to the management considerations, the hypothesis 3 is rejected. 


\section{Hypothesis 4:}

TV ads of life insurance and investing of Ma Insurance Company have been effective in customers decision to make purchase. Like the hypothesis 3 , hypothesis 4 is also rejected due to the confirmation of null hypothesis. In other words, the advertising was not effective in the customers decision to make purchase. In this step, AIDA model was used. In this model, the audiences are excluded from the advertising environment and seek the advertised product in the real world to achieve more information about the product. It was proved that, the advertising failed to persuade audiences to make purchase, consider it affordable, or recommend it to their friends and acquaintances.

As it was explained in the explanations of the hypothesis 3, as the customers found no will towards the product, it seems that they take no measure to search about it and finally to buy it. Consequently, as it was mentioned, the respective product fail to create such a willingness in the customers.

\section{References}

Amiri, A. (2006). Investigating the effectiveness of TV ads on opening Interest Free Loan accounts in Tejarat bank. Master of Business Administration, Faculty of Administrative Sciences, University of Shahid Beheshti.

Harati, S. M. (2006). Investigating the effectiveness of insurance industry advertisings. M.A. thesis of Business Administration, Faculty of Administrative Sciences, University of Shahid Behesht.

Irandoost, S. P. (2005). Investigating the effectiveness of TV ads on new services of Mellat Bank. M.A. thesis of Business Administration, Faculty of management, Tehran University.

Kelly, S. W., \& Turley, L.W. (2004). The Efect of content on perceived affect of super bowl commercials. Journal of Sport Management,18,101-142.

Kotler, P. (2005). Marketing management . In (11th Ed.), Pearson Education.

Kotler, P., \& Keller, K. L. (2006). Marketing management. In (12th Ed.), Prentice Hall.

Roosta, A., Venoos, F., \& Ebrahimi (2006). Marketing management.

Tellis, J. G. (2004). Effective advertising. Sage Publications.

\section{Copyrights}

Copyright for this article is retained by the author(s), with first publication rights granted to the journal.

This is an open-access article distributed under the terms and conditions of the Creative Commons Attribution license (http://creativecommons.org/licenses/by/4.0/). 